\title{
Pretreatment of Pussy Willow and Korean Pine Using Various lonic Liquids and their Mixtures with Organic Solvents for Enzymatic Saccharification
}

\author{
Song-Yi Han, ${ }^{\mathrm{a}}$ Chan-Woo Park, ${ }^{\mathrm{a}, \mathrm{b}}$ Eun-Ah Lee, ${ }^{\mathrm{a}, \mathrm{b}}$ Ji-Soo Park, ${ }^{\mathrm{a}, \mathrm{b}}$ Gu-Joong Kwon, ${ }^{\mathrm{a}, \mathrm{d}}$ \\ Nam-Hun Kim, a,b and Seung-Hwan Lee ${ }^{\text {a,b,c,* }}$
}

\begin{abstract}
Different ionic liquids (ILs) and their mixtures with organic solvents (OSs) were investigated to determine their effects on pretreatment for enzymatic saccharification of pussy willow and Korean pine. Combinations of three ILs, namely (1-ethyl-3-methylimidazolium acetate ([EMIM]Ac), 1-butyl-3methylimidazolium bromide ([BMIM] Br), and 1,3-dimethylimidazolium methyl sulfate ([MMIM]MeSO 4$)$ ) and three OSs (N,N-dimethylformamide (DMF), N,N-dimethylacetamide (DMAc), and dimethyl sulfoxide (DMSO)) were used. Acremonium cellulase and Optimash BG were used for enzymatic saccharification. The viscosity of ILs and their mixtures with OSs was reduced by adding and increasing the OS amount in mixtures. The viscosity of [BMIM]Br was considerably decreased by the addition of OSs. For both species, the water-soluble fractions (WSFs) obtained using pure ILs decreased with increasing OS content in mixtures. For all co-solvent systems, the WSFs for pussy willow were twice as large as those for Korean pine. For both species, the yields of glucose and xylose were higher for [EMIM]Ac and its mixtures with OSs than for [BMIM]Br, [MMIM] MeSO 4 , and their mixtures. However, only small differences between glycan and xylose yields among the products pretreated by [BMIM]Br, [MMIM]MeSO 4 , and their mixtures were observed. The overall xylose yields for pussy willow were higher than those for Korean pine for all pretreatments because xylan is the main hemicellulose component of hardwood.
\end{abstract}

Keywords: Pretreatment; Ionic liquid; Organic solvent; Pussy willow; Korean pine

Contact information: a: Institute of Forest Science, Kangwon National University, Chuncheon 24341, Republic of Korea; $b$ : Department of Forest Biomaterials Engineering, College of Forest and Environmental Sciences, Kangwon National University, Chuncheon 24341, Republic of Korea; c: Institute of Fermentation and Brewing, Kangwon National University, Chuncheon 24341, Republic of Korea; $d$ : Kangwon Institute of Inclusion Technology, Kangwon National University, Chuncheon 24341, Republic of Korea; * Corresponding author: lshyhk@kangwon.ac.kr

\section{INTRODUCTION}

Recently, pretreatment of lignocellulosic biomass using ionic liquids (ILs) as green solvents has attracted substantial attention because of advantages such as easy recovery, chemical stability, temperature stability, non-flammability, low vapor pressure, and wide range of available liquids (Cvjetko Bubalo et al. 2015; Halder et al. 2019; Han et al. 2020a). Despite their many advantages, several drawbacks of the pretreatment using ILs must be addressed. For example, the viscosity of 1-butyl-3-methylimidazolium chloride ([BMIM]Cl) is as high as $142 \mathrm{mPa} \cdot \mathrm{s}$ at $80{ }^{\circ} \mathrm{C}$, and the IL is found in the solid state at room temperature (Fendt et al. 2011). Thus, its dissolution capability is usually achieved at high temperatures that may lead to unstable IL properties, unwanted side reactions, and loss of treated biomass. Weerachanchai et al. (2012) reported that a significant loss of biomass 
yield resulted from the pretreatment with ILs ([EMIM]Ac, [MMIM]MeSO4, 1-ethyl-3methylimidazolium diethyl phosphate ([EMIM]DePO4) ) at high temperatures (150 and 180 ${ }^{\circ} \mathrm{C}$ ) due to the excessive degradation of carbohydrates including monosaccharides, oligosaccharides, furfural, and 5-hydroxymethylfurfural (HMF) into the WSF at high temperatures.

Several studies on the pretreatments using ILs have suggested the use of co-solvent systems with OSs to compensate the shortcomings of IL-based pretreatments. (Han et al. 2020b). The co-solvents would also enhance their solvating capability because these cosolvents could improve mass transportation by decreasing the solvent viscosity without having a significant influence on the specific interactions between cations and anions or between ILs and biomass components, especially cellulose (Andanson et al. 2014; Zhang et al. 2017). Wu et al. (2013) reported on the use of a co-solvent system of [EMIM]Ac and DMSO with different mixing ratios for the pretreatment of eucalyptus wood in order to improve the enzymatic saccharification yield. An appropriate ratio of [EMIM]Ac and DMSO can minimize [EMIM]Ac consumption while maintaining the pretreatment performance due to the viscosity reduction effect obtained by DMSO addition. Weerachanchai and Lee (2013) reported on a decrease in the viscosity of ILs ([BMIM]Cl and [EMIM]Ac) obtained by mixing the ILs with DMF, DMAc, DMSO, and ethanolamine that have high Hildebrand solubility parameters in order to increase the pretreatment capability for corncob and rice straw. The pretreatment using [EMIM]Ac and its mixture with DMAc (40 to 60\%) provided similar sugar conversion yield, extracted lignin content, and yield of regenerated biomass to those obtained using [EMIM]Ac only. Mai et al. (2014) proposed a microwave-assisted method for the pretreatment of rice straw using the [EMIM]Ac/DMSO co-solvent system. The microwave-assisted pretreatment provided at least 22 times faster enzymatic saccharification than that of un-treated rice straw due to more efficient lignin extraction, lesser content of crystalline cellulose, and lower residual ILs in the treated rice straw. Han et al. (2017, 2020a) reported the co-solvent systems of [EMIM]Ac/DMF and DMAc for improved enzymatic saccharification of pussy willow. Used as co-solvents, both DMF and DMAc enable higher biomass loadings by lowering the viscosity and the cost of the ILs used in the pretreatment. Pretreatment with [EMIM]Ac and its mixtures with DMF and DMAc at a content of more than 50\% showed the similar enzymatic saccharification efficiency to that obtained using pure [EMIM]Ac.

In this study, the co-solvent systems were prepared using different combinations of three ILs, namely [EMIM]Ac, [BMIM]Br, and [MMIM] MeSO 4 and three OSs, namely DMF, DMAc, and DMSO. Three ILs were selected because of their high solubility of all biomass components (Zhu et al. 2013; Cao et al. 2016). The effects of these co-solvent systems on the pretreatment for the enzymatic saccharification of pussy willow and Korean pine were investigated.

\section{EXPERIMENTAL}

\section{Materials}

The pussy willow (Salix gracilistyla Miq.) and Korean pine (Pinus koraiensis Siebold \& Zucc.) samples were ground to a particle size of less than 40 mesh and extracted at $85{ }^{\circ} \mathrm{C}$ for $5 \mathrm{~h}$ with an ethanol/benzene mixed solution $(1 / 2, \mathrm{v} / \mathrm{v})$ followed by vacuum drying at $85{ }^{\circ} \mathrm{C}$. [EMIM] Ac, [BMIM]Br, and [MMIM] MeSO 4 were purchased from IoLiTec (Heilbronn, Germany), and the other chemicals used in this study were purchased 
from Daejung Chemicals \& Metals (Siheung, Korea). Acremonium cellulase and Optimash BG were obtained from Meiji Seika Co. (Tokyo, Japan) and Genencor International, Inc. (Palo Alto, CA, USA), respectively.

\section{Chemical composition analysis}

The chemical composition of the raw materials was analyzed as follows. To measure the holocellulose content, the extracted sample $(1 \mathrm{~g})$ was reacted with the mixed solvent of $\mathrm{NaClO}_{2}(0.4 \mathrm{~g})$ and distilled water $(60 \mathrm{mg})$ mixed with acetic acid $(80 \mu \mathrm{L})$ in a water bath at $80{ }^{\circ} \mathrm{C}$ for $1 \mathrm{~h}$, and this procedure was repeated five times by adding the same amount of $\mathrm{NaClO}_{2}$ and acetic acid for complete removal of lignin. The delignified product was filtered, washed several times with distilled water, dried at $40{ }^{\circ} \mathrm{C}$ for $24 \mathrm{~h}$, and weighed to determine the holocellulose content (Wise et al. 1946). The holocellulose sample (0.6 g) was further treated by a $17.5 \%$ sodium hydroxide solution $(17.5 \mathrm{~mL})$ and neutralized using a $10 \%$ acetic acid solution $(28 \mathrm{~mL})$. After washing with distilled water, the filtered product was vacuum-dried at $40{ }^{\circ} \mathrm{C}$ to obtain $\alpha$-cellulose. The hemicellulose content was calculated by subtracting the $\alpha$-cellulose content from the holocellulose content. The Klason lignin content was determined as the insoluble residue amount obtained by the treatment with a $72 \%$ sulfuric acid solution for $1 \mathrm{~h}$ at room temperature, diluting to $3 \%$, and reacting in an autoclave $\left(1 \mathrm{~h}, 120^{\circ} \mathrm{C}\right)$.

\section{Pretreatment}

The mixture was prepared by mixing one of the three ILs ([EMIM]Ac, [BMIM]Br, and $[\mathrm{MMIM}] \mathrm{MeSO}_{4}$ ) and one of the three OSs (DMF, DMAc, and DMSO) at the weight ratios of $7 / 3,5 / 5$, and $3 / 7$. Wood flour (pussy willow and Korean pine) was added to ILs, OSs, and their mixtures with a solid loading of $15 \mathrm{wt} \%$. The mixtures were stirred with a vortex mixer and left to stand at $120^{\circ} \mathrm{C}$ for $2 \mathrm{~h}$ in a dry oven. The pretreated products were precipitated in distilled water to separate the WSF and the solvents. The precipitated products were vacuum-filtered using PTFE membrane filters (ADVANTEC®, Toyo Roshi Kaisha, Ltd., Tokyo, Japan), and the obtained residues were freeze-dried using an FDB5503 instrument (Operon Co., Ltd., Gimpo, Korea) and used for enzymatic saccharification and other characterizations.

\section{Enzymatic saccharification and acid hydrolysis}

Enzymatic saccharification was conducted in a shaking incubator $(150 \mathrm{rpm})$ at 50 ${ }^{\circ} \mathrm{C}$ for $72 \mathrm{~h}$. An enzyme cocktail of acremonium cellulase (15 FPU per gram of substrate) and Optimash BG $(0.2 \%, \mathrm{v} / \mathrm{v})$ was used as a supplement to $\beta$-xylosidase. The pretreated substrates $(200 \mathrm{mg})$ were added to the enzyme cocktail at a solid loading of $2 \%$ in a sodium acetate buffer $(50 \mathrm{mM}, \mathrm{pH} 5)$, and hydrolysates $(1 \mathrm{~mL})$ were aliquoted at 3, 6, 12, 24, 48, and $72 \mathrm{~h}$. After heating at $95{ }^{\circ} \mathrm{C}$ for $15 \mathrm{~min}$ in a heating block, the enzyme activation was stopped, and the samples were stored at $4{ }^{\circ} \mathrm{C}$ before HPLC separation.

Acid hydrolysis was also conducted according to the NREL protocol (Sluiter et al. 2008) for the compositional measurement of the monosaccharides in the pretreated product. The pretreated products $(100 \mathrm{mg})$ were added to a $72 \%$ sulfuric acid solution $(0.7$ $\mathrm{mL}$ ), and the mixture was thoroughly mixed using a vortex mixer and incubated in a shaking incubator for $1 \mathrm{~h}$ at $250 \mathrm{rpm}$. The reactant was diluted to $4 \%$ by adding deionized water $(19.4 \mathrm{~mL})$ and was reacted again at $120^{\circ} \mathrm{C}$ for $1 \mathrm{~h}$ in an autoclave. The hydrolysate was neutralized by adding a calcium carbonate solution. 
For HPLC measurements, both enzymatic and acidic hydrolysates were centrifuged at $7000 \mathrm{rpm}$ for $15 \mathrm{~min}$ and filtered using a syringe filter with a pore size of $0.2 \mu \mathrm{m}$ (Sartorius, Goettingen, Germany).

Analysis

The viscosities of ILs, OSs, and their mixtures were measured at $25{ }^{\circ} \mathrm{C}$ using an LVDV-II+ Brookfield viscometer (Brookfield Engineering Laboratories, Inc., Middleboro, MA, USA) with a spindle number of 18 (shear rate range: 0 to $132.0 / \mathrm{sec}$; viscosity range: 3 to $10,000 \mathrm{cP})$.

Morphology was observed using a scanning electron microscope (SEM, S-4800, Hitachi, Tokyo, Japan) at the Central Laboratory of Kangwon National University. The sample was freeze-dried and coated with platinum using a vacuum evaporator (JEE-400, JEOL Ltd., Tokyo, Japan) with an electric current of $20 \mathrm{~mA}$.

The monosaccharides were analyzed with an HPLC system (YL9100; Young Lin Instrument Co., Ltd., Anyang, Korea) equipped with an Aminex HPX-87P column (BioRad Laboratories, Inc., Hercules, CA, USA). The mobile phase was deionized water, and the flow rate was $0.6 \mathrm{~mL} / \mathrm{min}$ at $85{ }^{\circ} \mathrm{C}$. The glucose and xylose yields in the enzymatic hydrolysate were calculated according to Eq. 1:

$$
=\frac{\text { Mass of glucose }(\text { or xylose) in enzymatic hydrolysates }(\mathrm{g}) \times 0.9(0.88)}{\text { Mass of glucan (or xylan)in pretreated wood }(\mathrm{g}) \text { by acid hydrolysis }} \times 100 \text {. }
$$

\section{RESULTS AND DISCUSSION}

As shown in Table 1, according to the quantitative analyses, the $\alpha$-cellulose, hemicellulose, Klason lignin, and extractives contents of the un-treated Korean pine were $35.6,23.7,38.5$, and $6.3 \mathrm{wt} \%$, respectively. Compared to pussy willow, the hemicellulose content and the lignin and extractives of Korean pine contents were lower and higher, respectively.

Table 1. Chemical Composition of the Un-treated Wood

\begin{tabular}{|l|c|c|}
\hline Compounds & Pussy Willow (wt\%) & Korean Pine (wt\%) \\
\hline a-cellulose & 37.6 & 35.6 \\
\hline Hemicellulose & 35.9 & 23.7 \\
\hline Klason lignin & 25.0 & 38.5 \\
\hline Extractives & 5.6 & 6.3 \\
\hline
\end{tabular}

Figure 1 shows the viscosity of ILs and their mixtures with different ratios of ILs such as [EMIM]Ac, [MMIM] MeSO 4 , and [BMIM]Br, and OSs such as DMF, DMAC, and DMSO. The use of the mixture of ILs and OSs in order to reduce the viscosity of ILs has been suggested in several studies, and it was shown that the addition of the OS does not significantly affect the specific interactions between cations and anions or between the IL and the lignocellulosic biomass (Andanson et al. 2014; Han et al. 2017; Wu et al. 2013). The viscosity of [BMIM] Br was more than $3000 \mathrm{cP}$, while the viscosities of the other ILs 
([EMIM]Ac and [MMIM]MeSO 4 ) were lower than $150 \mathrm{cP}$. The viscosities of DMF, DMAC, and DMSO were 1.35, 1.53, and $2.64 \mathrm{cP}$, respectively. The addition of OSs to ILs dramatically decreased the viscosity of ILs and their mixtures, showing values lower than $100 \mathrm{cP}$, regardless of the IL type. The viscosity of the mixtures with DMF was lowest in all samples with different IL/OS ratios. In particular, when 30\% DMF was added to [BMIM]Br, the viscosity drastically decreased by approximately 90 times from $3090 \mathrm{cP}$ to $34.7 \mathrm{cP}$ and was 51.8 and $98.6 \mathrm{cP}$ in mixtures with $30 \%$ DMAc and DMSO, respectively. This low viscosity was helpful for handling at a relatively high biomass loading of $15 \%$ in ILs. Wu et al. (2013) also reported the effect of DMSO addition on the viscosity of [EMIM]Ac, showing that an exponential decrease in the viscosity is obtained by increasing the DMSO ratio in the mixtures. Yang et al. (2017) used four organic solvents, i.e., DMF, DMAc, DMSO, and pyridine (PYR) for lowering the viscosity of [BMIM]Cl. DMF showed the most considerable effect to lower the viscosity of pure IL, which is similar with our results. They have also studied the microstructure of the mixtures using FTIR, aiming to understand further the relationship between the properties and the structures of the mixtures. They reported that $\mathrm{C} 4-\mathrm{H}$ in the IL and PYR may form the weakest hydrogenbonding but other solvents did not show significant hydrogen-bonding formations.
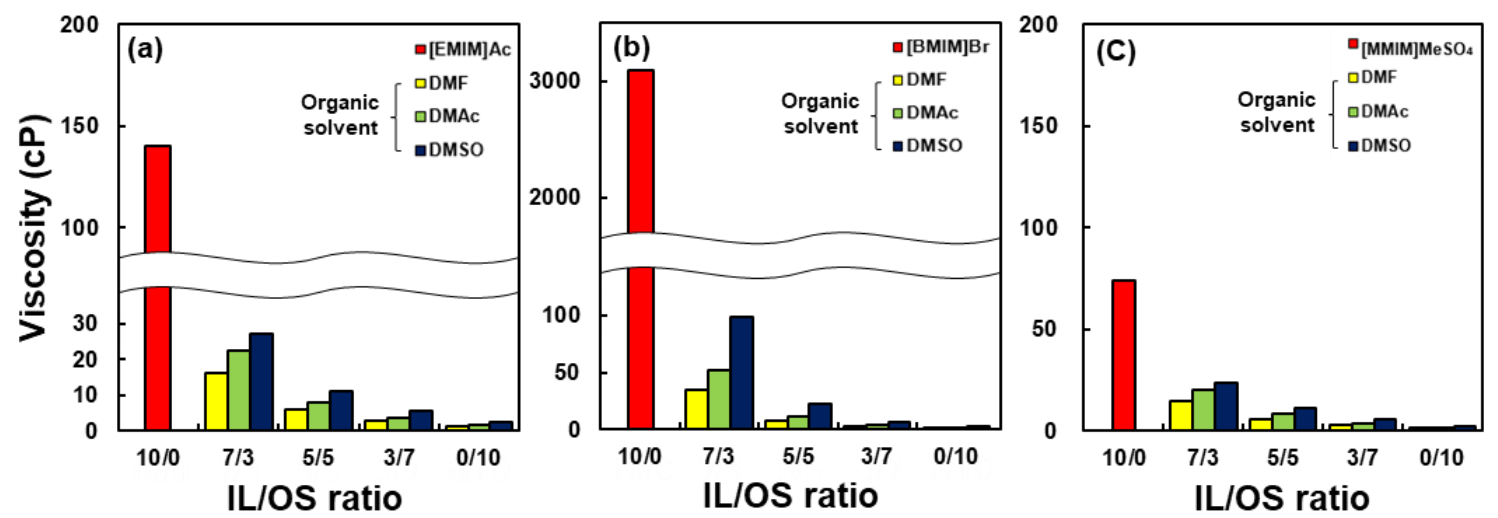

Fig. 1. Effect of ILs/OSs ratio on the viscosity of the mixtures

Figure 2 shows the obtained WSFs of the pussy willow and Korean pine pretreated with ILs, OSs, and their mixtures with different mixing ratios. Most of the components in WSF would be the small molecular products from hemicellulose and lignin. Silva et al. (2011) reported that a cellulose-rich fraction could be recovered as a consequence of the loss of water-soluble lignin and hemicellulose during precipitation of the dissolved product. For pussy willow, the WSF of the products obtained using pretreatments with pure ILs, i.e., [EMIM]Ac, [BMIM]Br, and [MMIM] $\mathrm{MeSO}_{4}$ were 23.0, 23.1 and 23.5\%, respectively.

By contrast, the WSFs for Korean pine were 9.7, 12.7, and 13.0, approximately twice smaller than the corresponding values for pussy willow. For both species, the values obtained using pretreatment with pure ILs showed a decreasing trend with increasing OS in the mixtures, but the amount of the decrease was small. This result indicates that hardwood (pussy willow) is more susceptible to be dissolved in ILs than softwood (Korean pine). 

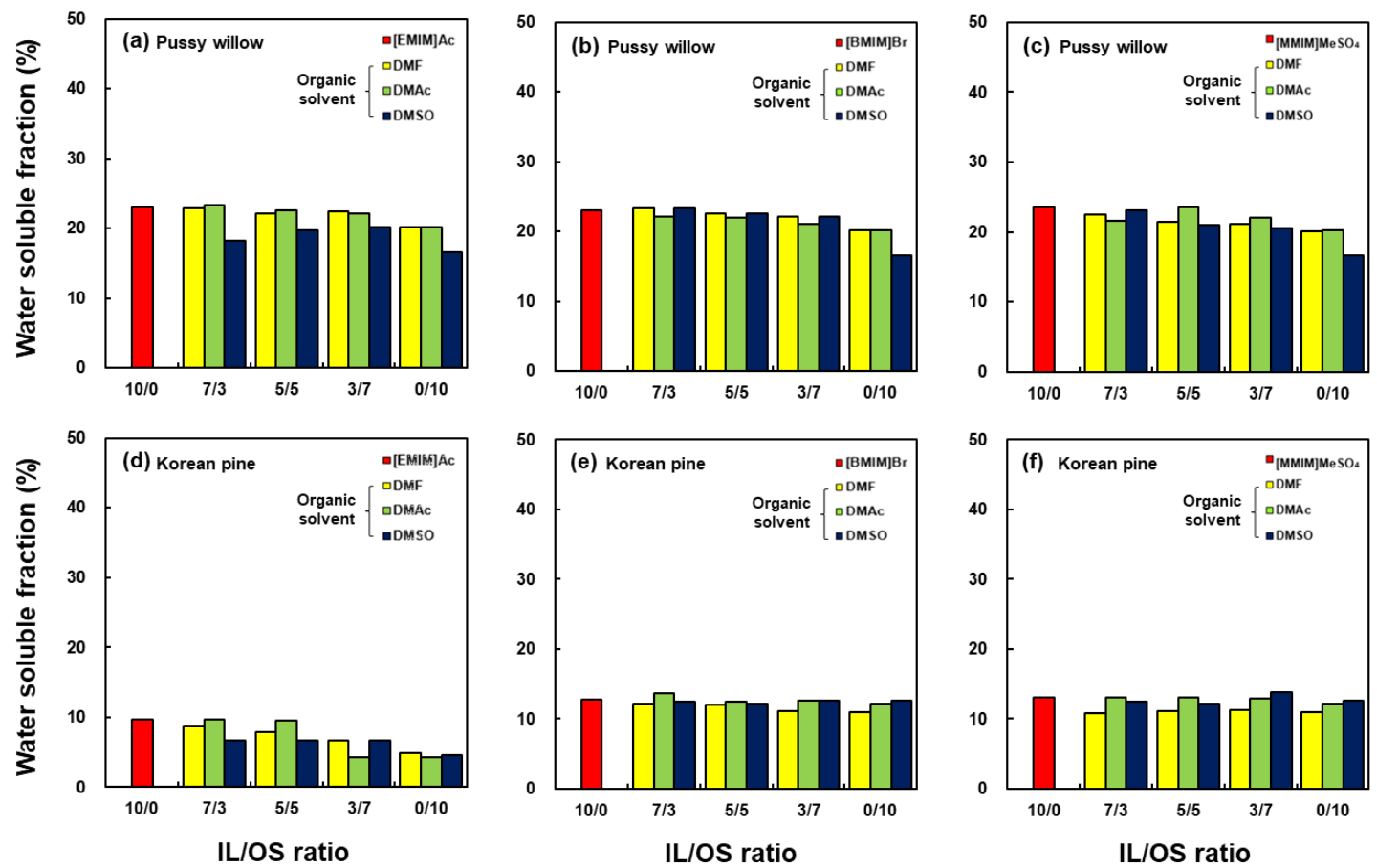

Fig. 2. Effect of the ILs/OSs ratio on the WSF of pussy willow and Korean pine

The surface morphology of the un-treated and pretreated products by ILs, OSs, and their mixtures of pussy willow (Fig. 3) and Korean pine (Fig. 4) was observed by SEM. Un-treated samples of both species exhibited a highly ordered fibrillar and compact morphology. In contrast, all pretreated products significantly alter the fibrillar structure and the surfaces became rougher after pretreatment due to the disruption of the cell wall structure (Weerachanchai and Lee 2013). Some lignin particles extracted from the cell wall were also observed in Korean pine pretreated with [MMIM] MeSO 4 (Fig. 4g). IL can cause the cleavage of the chemical bonds between lignin and hemicellulose and the disruption of hydrogen bonding in the cellulosic network, resulting in the increase of the porosity and the surface area (Alayoubi et al. 2020). It will promote an increase in enzymatic efficiency (Dong et al. 2019). Among the ILs, the pretreatment with [EMIM]Ac significantly increased the porosity and surface area than other ILs used. Hu et al. (2018) also reported that smooth and compact morphology of un-treated sample limited cellulase contact sites, lowering enzymatic hydrolysis efficiency, whereas pretreatment using [BMIM] $\mathrm{BF}_{4}$ made the loose porous structure, resulting in the increase in enzymatic hydrolysis efficiency.

Figures 5, 6 and 7, 8 show the effect of the IL/OS ratio on the yield of glucose and xylose obtained by enzymatic saccharification from the pretreated pussy willow and Korean pine, respectively. The yields of glucose and xylose were calculated based on the mass of glucan and xylan in the pretreated product obtained by acid hydrolysis. The yields of glucose and xylose were 14.34 and $8.03 \%$ in un-treated pussy willow and 8.53 and $7.86 \%$ in un-treated Korean pine, respectively, for $72 \mathrm{~h}$ saccharification. In all samples, both yields increased with increasing saccharification time, showing a rapidly increasing trend up to the saccharification time of $12 \mathrm{~h}$ and followed by a gradual increase. 

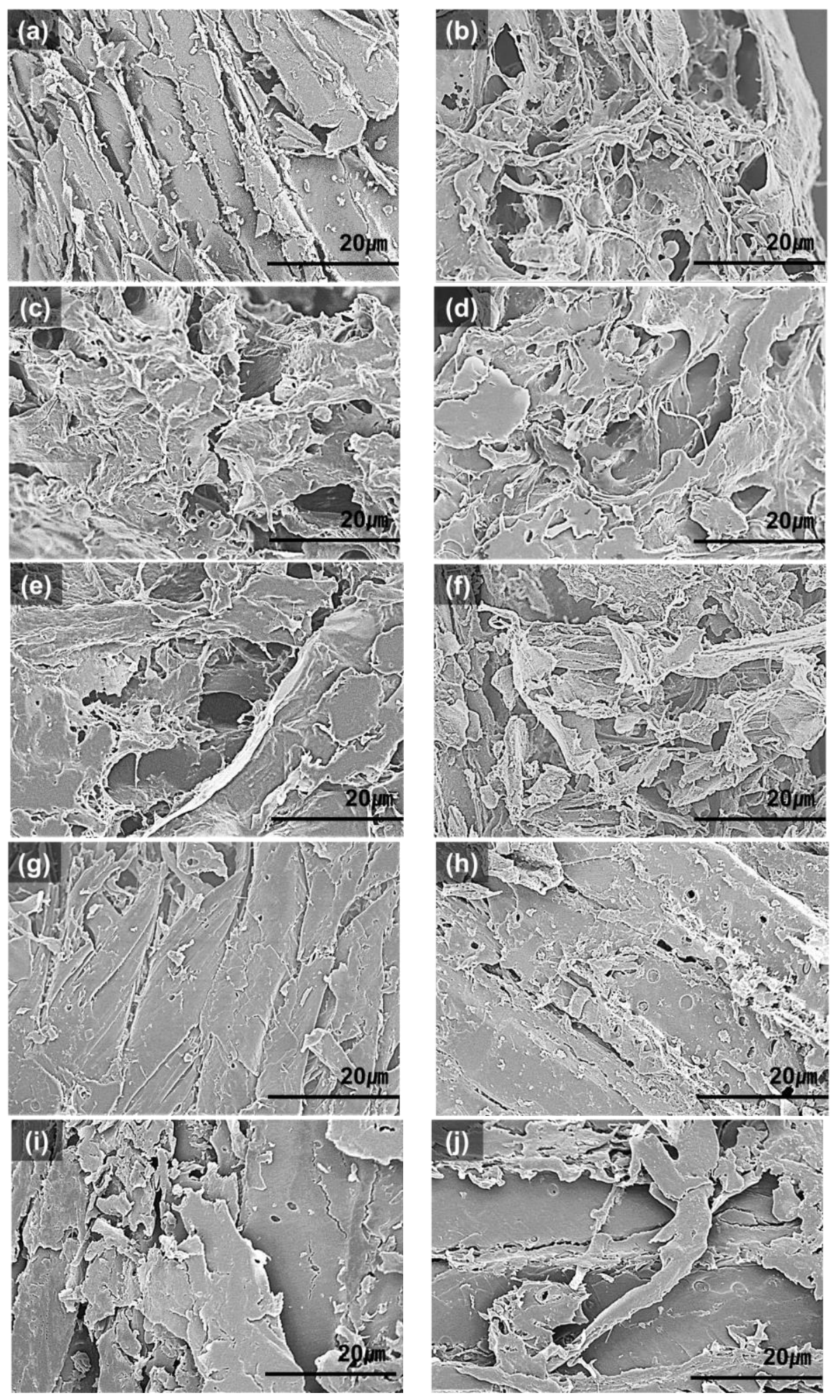

Fig. 3. Morphology of un-treated product (a) and pretreated products by [EMIM]Ac (b), its mixtures with $50 \%$ OSs (DMF (c); DMAc (d); DMSO (e)), [BMIM]Br (f), [MMIM]MeSO 4 (g) and OSs (DMF (h); DMAc (i); DMSO (j)) of pussy willow 

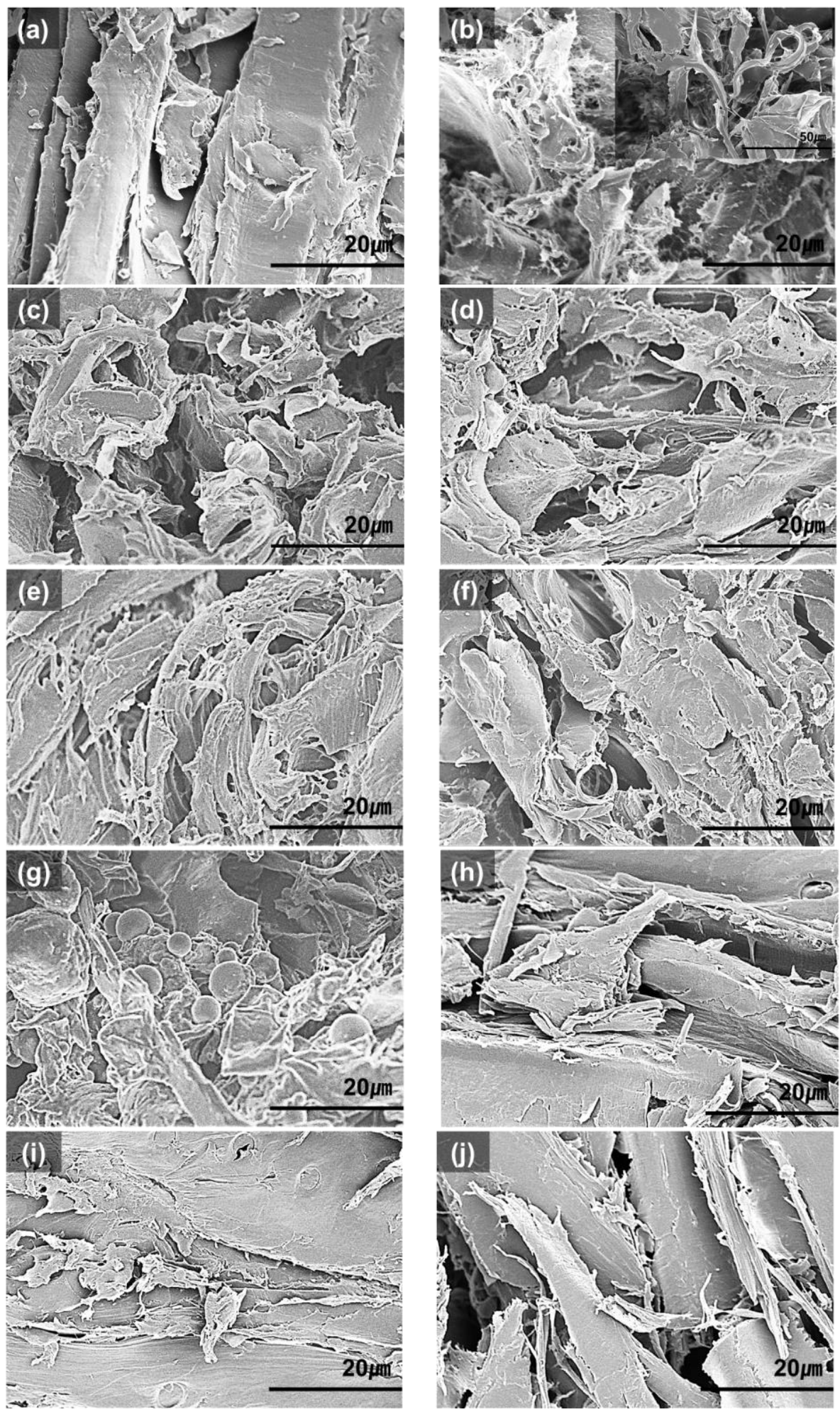

Fig. 4. Morphology of un-treated product (a) and pretreated products by [EMIM]Ac (b), its mixtures with $50 \%$ OSs (DMF (c); DMAc (d); DMSO (e)), [BMIM]Br (f), [MMIM]MeSO 4 (g), and OSs (DMF (h); DMAc (i); DMSO (j)) of Korean pine 

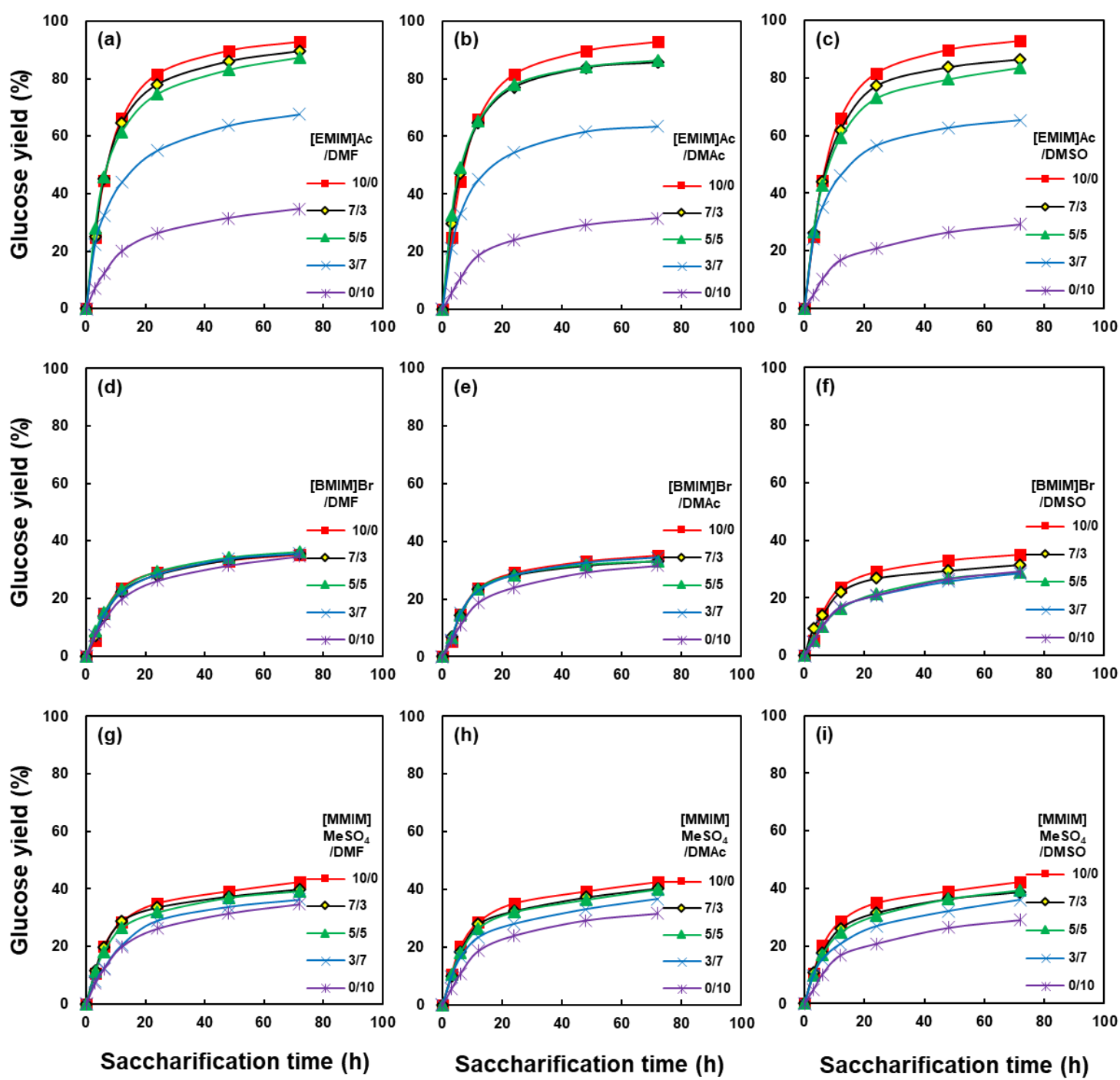

Fig. 5. Effect of the IL/OS ratio on the glucose yield of enzymatic saccharification for pretreated pussy willow 

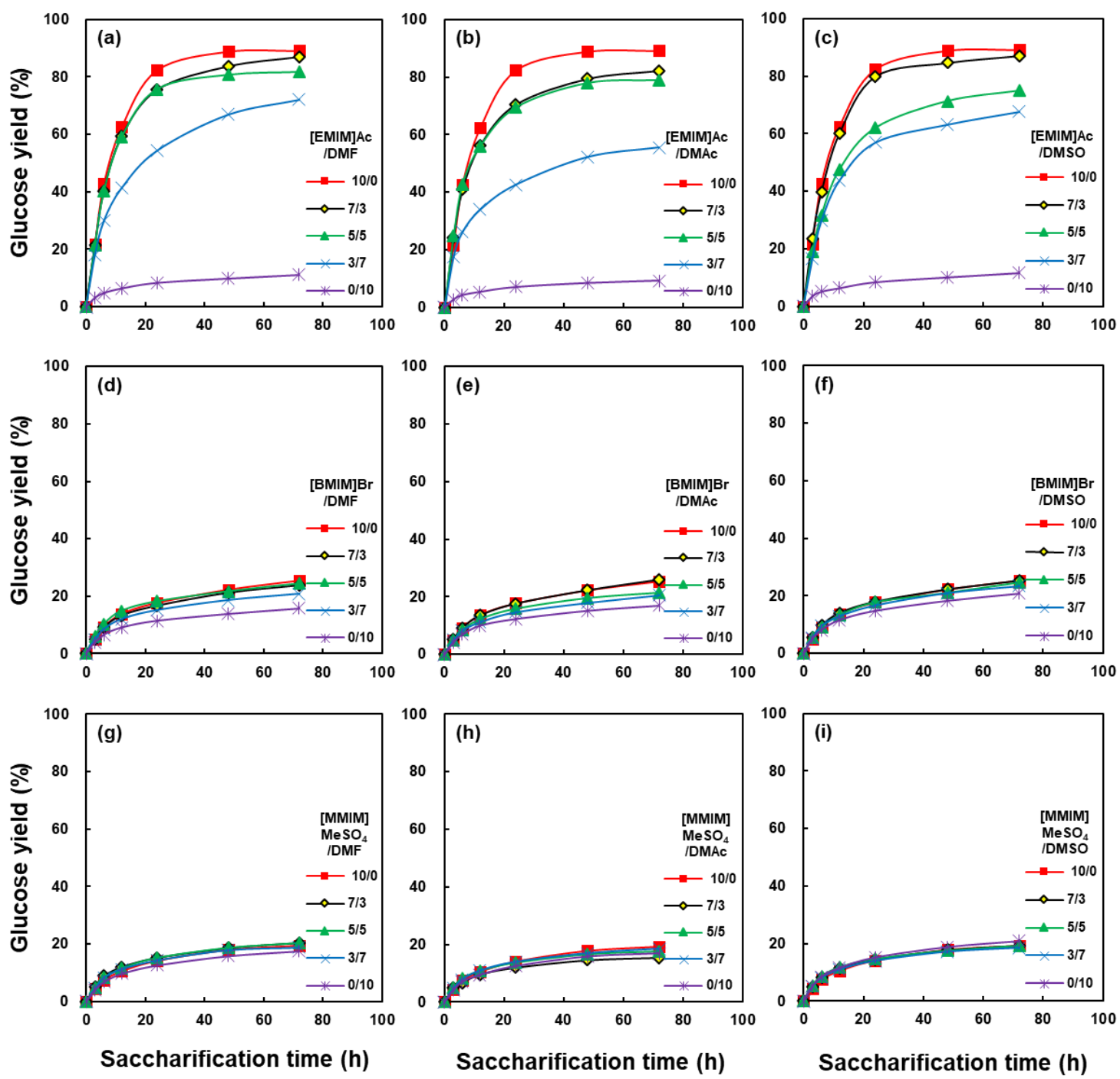

Fig. 6. Effect of the IL/OS ratio on the glucose yield of enzymatic saccharification for pretreated Korean pine 

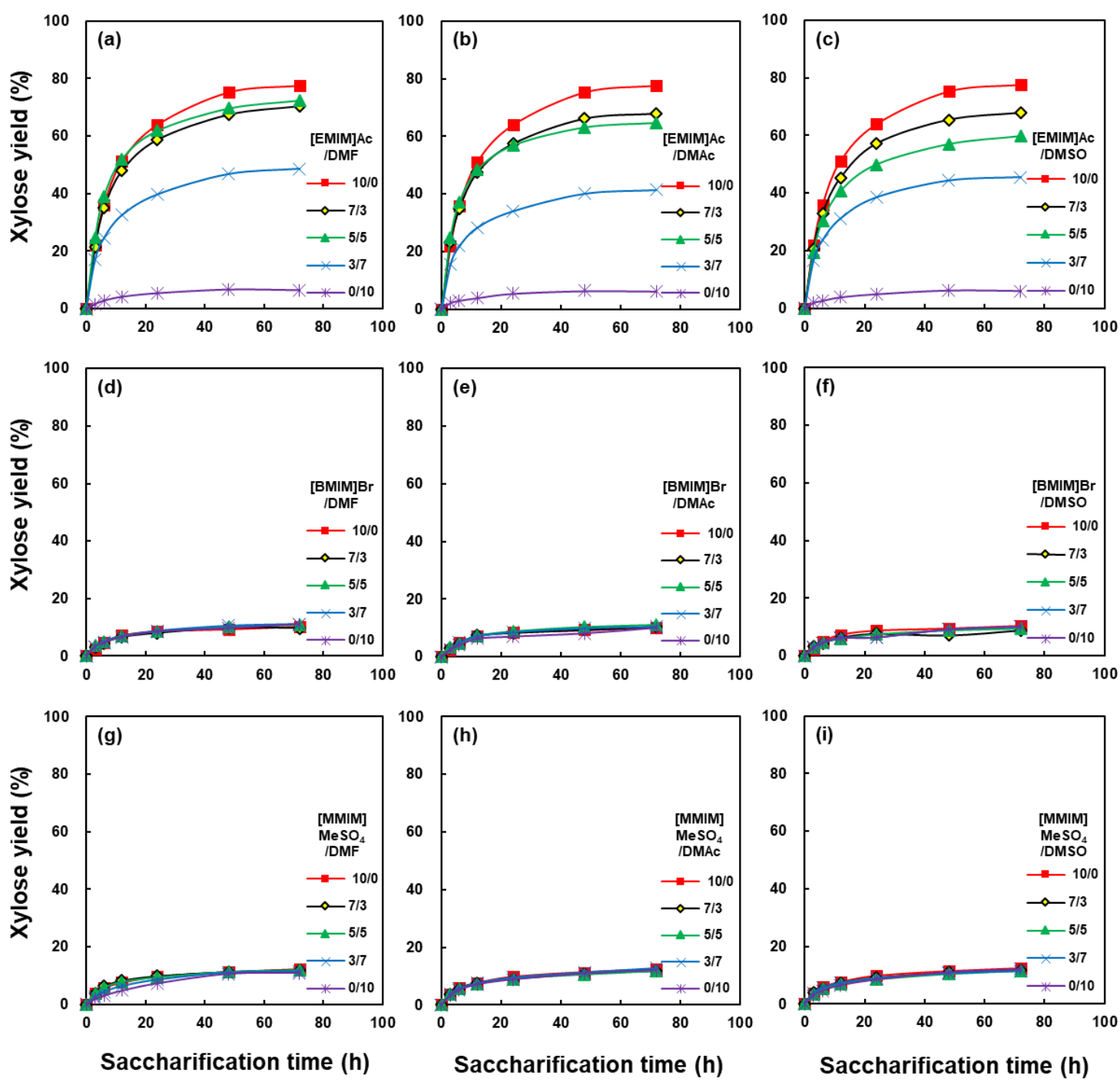

Fig. 7. Effect of the IL/OS ratio on the xylose yield of enzymatic saccharification for pretreated pussy willow 

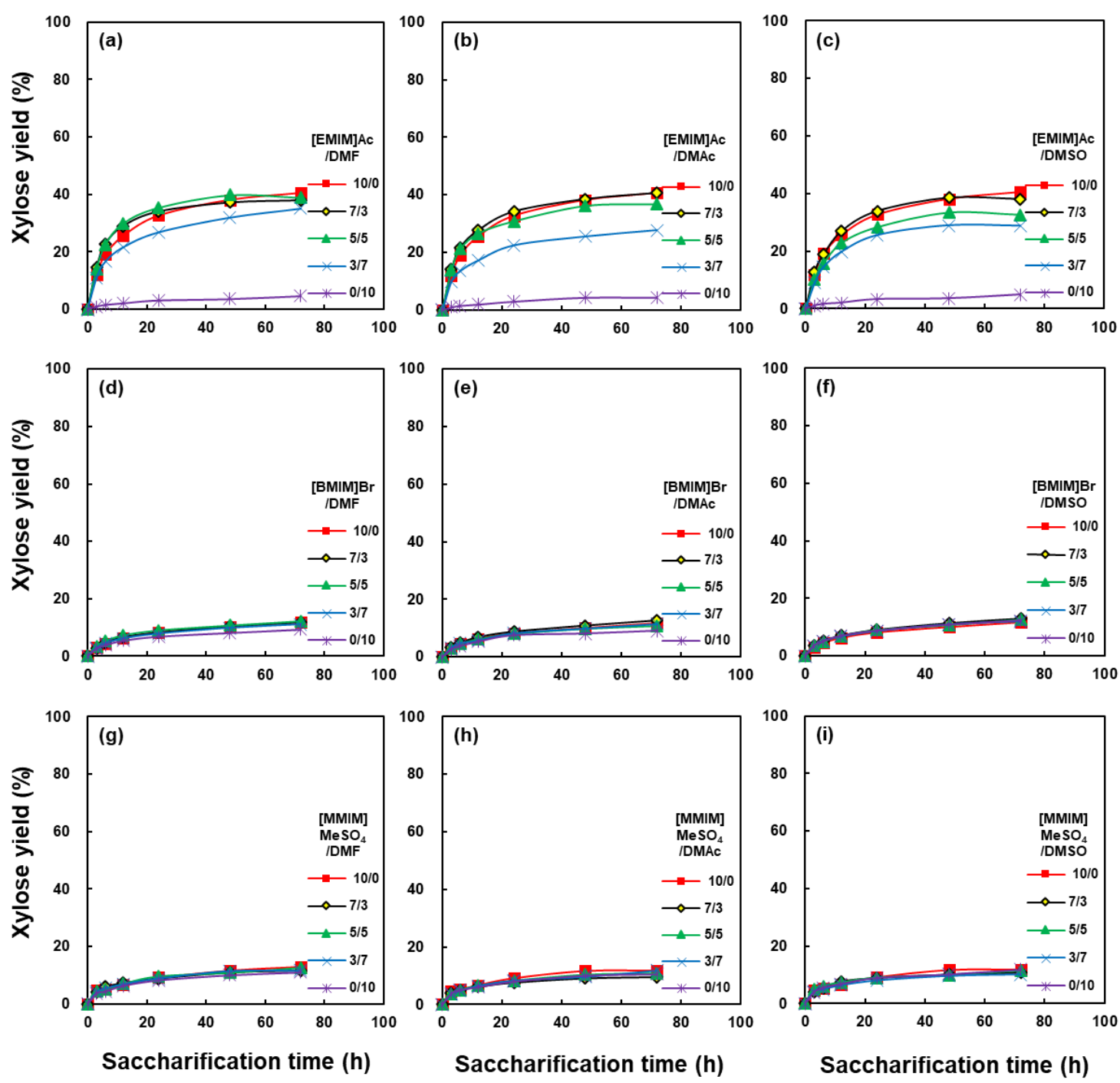

Fig. 8. Effect of the IL/OS ratio on the xylose yield of enzymatic saccharification for pretreated Korean pine

In both species, all saccharification yields were higher in [EMIM]Ac and its mixtures than in [BMIM]Br, [MMIM] $\mathrm{MeSO}_{4}$, and their mixtures. However, there was no significant difference for both saccharification yields from those obtained for the products pretreated by $[\mathrm{BMIM}] \mathrm{Br}$, [MMIM]MeSO 4 , and their mixtures. Based on the saccharification time of $72 \mathrm{~h}$, for pussy willow, the glucose yields were in the range of 28.5 to $35.1 \%$ and 36.0 to $42.4 \%$ in [BMIM] Br and its mixtures and [MMIM] $\mathrm{MeSO}_{4}$ and its mixtures, respectively, while for Korean pine, the corresponding glucose yields were in the range of 20.5 to $25.5 \%$ and 15.4 to $19.3 \%$, respectively. Xylose yields in both ILs ([BMIM] $\mathrm{Br}$ and [MMIM]MeSO 4 ) and their mixtures were less than $10 \%$ for both species, showing slightly larger values in hardwood than in softwood. For both species, these saccharification yields were not significantly different from those obtained from the 
product pretreated by the pure OS, showing no effect of ILs pretreatment on the improvement of enzymatic saccharification.

For both species, differences in the yields of glucose and xylose were obtained for the products pretreated by [EMIM]Ac and its mixtures. For the mixture with $50 \%$ or less of OS for both species, the glucose yield was found to be greater than $70 \%$ for the saccharification time of $72 \mathrm{~h}$, regardless of the OS type. The mixture with $70 \%$ OS amount showed greater than $50 \%$ glucose yield for both species, and are still higher than those obtained using the pure OS. The glucose yields for pussy willow were higher by approximately 34.7, 31.6, and 29.1\% for DMF, DMAc, and DMSO, respectively, while increases of 17.5, 17.0, and 19.3\% were obtained for Korean pine. While Korean pine and pussy willow showed similar trends, the yields for Korean pine were slightly smaller than those for pussy willow. The dependence of the xylose yield on the IL/OS ratio was also similar to that for the glucose yield for both species. However, the overall values obtained after saccharification for $72 \mathrm{~h}$ were higher for pussy willow than for Korean pine because xylan is the main hemicellulose component in hardwood.

\section{CONCLUSIONS}

1. Pretreatments using three different ionic liquids (ILs), namely [EMIM]Ac, [BMIM]Br, and $[\mathrm{MMIM}] \mathrm{MeSO}_{4}$ and their mixtures obtained by combinations with three different organic solvents (OSs), namely dimethyl formamide (DMF), $N, N$-dimethylacetimide (DMAc), and dimethyl sulfoxide (DMSO), were conducted to improve the enzymatic saccharification of pussy willow and Korean pine.

2. The viscosity was reduced by increasing the OSs amount in the mixtures, regardless of the solvent type. In particular, the viscosity of [BMIM]Br was drastically decreased by OS addition.

3. For both species, water-soluble fractions (WSFs) obtained using pure ILs decreased with increasing OS amount in the mixtures, and the WSFs for pussy willow were twice as large as those of Korean pine.

4. For both species, higher yields of glucose and xylose were obtained using [EMIM]Ac and its mixtures than using [BMIM]Br, [MMIM] $\mathrm{MeSO}_{4}$, and their mixtures. However, for both glucose and xylose, the differences between the products obtained using pretreatment by [BMIM]Br, [MMIM] $\mathrm{MeSO}_{4}$, and their mixtures were small. 


\section{ACKNOWLEDGMENTS}

This study was funded by the Basic Science Research Program through the National Research Foundation of Korea (NRF) funded by the Ministry of Education (Grant No. 2018R1A6A1A03025582).

\section{REFERENCES CITED}

Alayoubi, R., Mehmood, N., Husson, E., Kouzayha, A., Tabcheh, M., Chaveriat, L., Sarazin, C., and Gosselin, I. (2020). "Low temperature ionic liquid pretreatment of lignocellulosic biomass to enhance bioethanol yield," Renewable Energy 145, 18081816. DOI: 10.1016/j.renene.2019.07.091

Andanson, J.-M., Bordes, E., Devémy, J., Leroux, F., Pádua, A. A. H., and Gomes, M. F. C. (2014). "Understanding the role of co-solvents in the dissolution of cellulose in ionic liquids," Green Chemistry 16, 2528-2538. DOI: 10.1039/c3gc42244e

Cao, Y., Zhang, R., Cheng, T., Guo, J., Xian, M., and Liu, H. (2016). "Imidazoliumbased ionic liquids for cellulose pretreatment: Recent progresses and future perspectives," Applied Microbiology and Biotechnology 101(2), 521-532. DOI: 10.1007/s00253-016-8057-8

Cvjetko Bubalo, M., Vidović, S., Radojčić Redovniković, I., and Jokić, S. (2015). "Green solvents for green technologies," Journal of Chemical Technology and Biotechnology 90(9), 1631-1639. DOI: 10.1002/jctb.4668

Dong, M., Wang, S., Xu, F., Wang, J., Yang, N., Li, Q., Chen, J., and Li, W. (2019). "Pretreatment of sweet sorghum straw and its enzymatic digestion: Insight into the structural changes and visualization of hydrolysis process," Biotechnology for Biofuels 12(1), 1-11. DOI: 10.1186/s13068-019-1613-6

Fendt, S., Padmanabhan, S., Blanch, H. W., and Prausnitz, J. M. (2011). "Viscosities of acetate or chloride-based ionic liquids and some of their mixtures with water or other common solvents," Journal of Chemical \& Engineering Data 56(1), 31-34. DOI: 10.1021/je1007235

Halder, P., Kundu, S., Patel, S., Setiawan, A., Atkin, R., Parthasarthy, R., Paz-Ferreiro, J., Surapaneni, A., and Shah, K. (2019). "Progress on the pre-treatment of lignocellulosic biomass employing ionic liquids," Renewable and Sustainable Energy Reviews 105, 268-292. DOI: 10.1016/j.rser.2019.01.052

Han, S. Y., Park, C. W., Kim, N. H., and Lee, S. H. (2017). "Co-solvent system of [EMIM]Ac and DMF to improve the enzymatic saccharification of pussy willow (Salix gracilistyla Miq.)," Holzforschung 71(1), 43-50. DOI: 10.1515/hf-2016-0042

Han, S.-Y., Park, C.-W., Febrianto, F., Kim, N.-H., and Lee, S.-H. (2020a). "Pretreatment with [EMIM]Ac/DMAc co-solvent to improve enzymatic saccharification of pussy willow (Salix gracilistyla Miq.)," BioResources 15(1), 187-198. DOI: 10.15376/biores.15.1.187-198

Han, S.-Y., Park, C.-W., Kwon, G.-J., Kim, N.-H., and Lee, S.-H. (2020b). "Ionic liquid pretreatment of lignocellulosic biomass," Journal of Forest and Environmental Science 36(2), 69-77. DOI: 10.7747/JFES.2020.36.2.69

Hu, X., Cheng, L., Gu, Z., Hong, Y., Li, Z., and Li, C. (2018). "Effects of ionic liquid/water mixture pretreatment on the composition, the structure and the enzymatic 
hydrolysis of corn stalk," Industrial Crops and Products 122, 142-147. DOI:

10.1016/j.indcrop.2018.05.056

Mai, N. L., Ha, S. H., and Koo, Y.-M. (2014). "Efficient pretreatment of lignocellulose in ionic liquids/co-solvent for enzymatic hydrolysis enhancement into fermentable sugars," Process Biochemistry 49(7), 1144-1151. DOI:

10.1016/j.procbio.2014.03.024

Silva, A. S., Lee, S. H., Endo, T., and Bon, E. P. S. (2011). "Major improvement in the rate and yield of enzymatic saccharification of sugarcane bagasse via pretreatment with the ionic liquid 1-ethyl-3-methylimidazolium acetate ([Emim] [Ac])," Bioresource Technology 102(22), 10505-10509. DOI: 10.1016/j.biortech.2011.08.085

Sluiter, A. D., Hames, B., Ruiz, R., Scarlata, C., Sluiter, J., Templeton, D., and Crocker, D. (2008). Determination of Structural Carbohydrates and Lignin in Biomass (NREL/TP-510-42618), National Renewable Energy Laboratory, Golden, CO, USA.

Weerachanchai, P., Chen, Z., Leong, S. S. J, Chang, M. W., and Lee, J.-M. (2012). "Hildebrand solubility parameters of ionic liquids: Effects of ionic liquid type, temperature and DMA fraction in ionic liquid," Chemical Engineering Journal 213, 356-362. DOI: 10.1016/j.cej.2012.10.012

Weerachanchai, P., and Lee, J. M. (2013). "Effect of organic solvent in ionic liquid on biomass pretreatment," ACS Sustainable Chemistry \& Engineering 1(8), 894-902. DOI: $10.1021 / \mathrm{sc} 300147 \mathrm{f}$

Wise, L. E., Murphy, M., and D'Addieco, A. A. (1946). "Chlorite holocellulose, its fractionation and bearing on summative wood analysis and on studies on the hemicelluloses," Paper Trade Journal 122 (2), 35-43.

Wu, L., Lee, S. H., and Endo, T. (2013). "Effect of dimethyl sulfoxide on ionic liquid 1ethyl-3-methylimidazolium acetate pretreatment of eucalyptus wood for enzymatic hydrolysis," Bioresource Technology 140, 90-96. DOI: 10.1016/j.biortech.2013.04.072

Yang, F., Wang, X., Tan, H., and Liu, Z. (2017). "Improvement the viscosity of imidazolium-based ionic liquid using organic solvents for biofuels," Journal of Molecular Liquids 248, 626-633. DOI: 10.1016/j.molliq.2017.10.107

Zhang, J., Wu, J., Yu, J., Zhang, X., He, J., and Zhang, J. (2017). "Application of ionic liquids for dissolving cellulose and fabricating cellulose-based materials: state of the art and future trends," Materials Chemistry Frontiers 1(7), 1273-1290. DOI: 10.1039/C6QM00348F

Zhu, Y.-H., Tang, K. Y.-T., and Hosmane, N. S. (2013). "Applications of ionic liquids in lignin chemistry," in: Ionic Liquids - New Aspects for the Future, Kadokawa, J. (ed.), IntechOpen: London, UK, Chapter 13. DOI: 10.5772/51161

Article submitted: March 31, 2020; Peer review completed: June 20, 2020; Revised version received and accepted: November 13, 2020; Published: November 24, 2020. DOI: 10.15376/biores.16.1.455-469 